\title{
A unique serine-rich repeat protein (Srr-2) and
novel surface antigen $(\varepsilon)$ associated with a virulent
lineage of serotype III Streptococcus agalactiae \\ Correspondence \\ L. Jeannine Brady \\ jbrady@dental.ufl.edu \\ Received 13 September 2005 \\ Revised 2 January 2006 \\ Accepted 5 January 2006

\author{
Kyle N. Seifert, ${ }^{1}$ Elisabeth E. Adderson, ${ }^{2}$ April A. Whiting, ${ }^{3}$ \\ John F. Bohnsack, ${ }^{3}$ Paula J. Crowley ${ }^{4}$ and L. Jeannine Brady ${ }^{4}$ \\ ${ }^{1}$ Department of Biology, James Madison University, Harrisonburg, VA 22807, USA \\ 2Department of Infectious Diseases, St Jude Children's Research Hospital, Memphis, \\ TN 38105, USA \\ ${ }^{3}$ Department of Pediatrics, University of Utah Health Sciences Center, Salt Lake City, \\ UT 84132, USA \\ ${ }^{4}$ Department of Oral Biology, College of Dentistry, University of Florida, Gainesville, FL 32610, \\ USA
} \\ Group B streptococci (GBS) are pathogens of both neonates and adults, with serotype III strains in particular being associated with invasive disease and meningitis. In this study, a novel GBS surface antigen, $\varepsilon$, was found to be co-expressed with the previously reported $\delta$ antigen on an identical subset of serotype III GBS. Expression of $\delta / \varepsilon$ on the surface of serotype III GBS was shown to distinguish the restriction digest pattern (RDP) III-3 and multilocus sequence typing (ST)-17 lineage. $\varepsilon$-Specific antibodies were reactive with a unique, high-molecular-mass, serine-rich repeat protein (Srr-2) found exclusively in RDP III-3 strains. The gene encoding Srr-2 was located within a putative accessory secretory locus that included sec $Y 2$ and $\sec A 2$ homologues and had a genetic organization similar to that of the secY2/A2 locus of staphylococci. In contrast, serotype III $\delta / \varepsilon$-negative strains and strains representative of serotypes la, lb, lc and II shared a common Srr-encoding gene, srr-1, and an organization of the secY2/A2 locus similar to that of previously reported serotype lc, $\delta / \varepsilon$-negative serotype III and serotype V GBS strains. Representative serotype III $\delta / \varepsilon$-positive strains had $L_{90}$ values $3-4$ logs less than those of serotype III $\delta / \varepsilon$-negative strains in a neonatal mouse model of infection. These results indicate that the RDP III-3/ST-17 lineage expresses Srr-2 and is highly virulent in an in vivo model of neonatal sepsis.
}

\section{INTRODUCTION}

Lancefield group B streptococci (GBS) are a major cause of neonatal sepsis (Baker \& Edwards, 2001) and are also important pathogens in adults, particularly those with underlying chronic medical conditions (Farley, 2001). There are two main clinical forms of neonatal GBS disease, early- and lateonset disease (Ferrieri, 1985; Baker \& Edwards, 2001). Earlyonset disease accounts for $80 \%$ of all GBS infections. These infections occur within the first week of life and are vertically transmitted from mother to infant. Each of the nine

\footnotetext{
Abbreviations: GBS, group B streptococci; HRP, horseradish peroxidase; MLST, multilocus sequence typing; RDP, restriction digest pattern; RIA, radioimmunoassay; Srr, serine-rich repeat; ST, sequence type.

The GenBank/EMBL/DDBJ accession numbers for the sequences of the secY2/A2 loci from GBS strains 874391 and J48 reported in this paper are AY669067 and DQ174691, respectively.
}

serotypes of GBS has been isolated from infants suffering from early-onset disease; however, serotypes III and V cause the majority of these infections. Late-onset disease occurs from 1 week to 3 months after birth. Serotype III GBS is responsible for $\sim 90 \%$ of these infections as well as $90 \%$ of cases of meningitis, irrespective of the time of onset of disease (Baker \& Edwards, 2001). Serotype III organisms are also the second most common serotype identified in invasive adult infections (Tyrrell et al., 2000).

A number of surface antigens associated with GBS have been identified. Wilkinson and Eagon first described the cprotein in 1971 (Wilkinson \& Eagon, 1971). It was subsequently discovered that c-protein typing serum recognizes at least four antigenic moieties, $\alpha, \beta$ (Wilkinson \& Eagon, 1971; Johnson \& Ferrieri, 1984; Bevanger, 1985), $\gamma$ and $\delta$ (Brady et al., 1988; Chun et al., 1991). The last two markers were identified by residual seroreactivity after exhaustive adsorption of the c-protein typing reagent with strains 
known to express $\alpha$ and $\beta$. Genes encoding the $\alpha$ and $\beta$ proteins have been cloned (Cleat \& Timmis, 1987; Michel et al., 1991) and the proteins characterized (Russell-Jones \& Gotschlich, 1984; Michel et al., 1991; Gravekamp et al., 1996; Maeland et al., 1997; Ustinovitch et al., 1999; Areschoug et al., 2002; Auperin et al., 2005). $\alpha$ and $\beta$ are expressed predominantly by serotypes Ia, Ib and II. The $\gamma$ antigen is an amino-terminus variant of the $\alpha$ protein (L. C. Madoff, personal communication). The genetic basis for expression of the $\delta$ antigen is unknown. It is associated almost exclusively with serotype III strains (Chun et al., 1991). The $\delta$ antigen is immunologically distinct from protein Rib, another GBS antigen associated primarily with serotype III organisms (Stalhammar-Carlemalm et al., 1993).

High-molecular-mass streptococcal and staphylococcal serinerich repeat (Srr) proteins are encoded within operons containing a dedicated secretion system (Wu et al., 1998; Bensing \& Sullam, 2002; Stephenson et al., 2002; Takamatsu et al., 2004b; Siboo et al., 2005). Many of these highly glycosylated, surfacelocalized proteins have adhesive functions. In the present study, an antigenic marker, designated $\varepsilon$, was identified that is co-expressed with the $\delta$ antigen on all $\delta$-positive serotype III GBS strains. Cell surface expression of this novel immunological reactivity correlates with the presence of a unique ORF, srr-2, contained within a genetic locus that includes homologues of secA2 and secY2 (Bensing \& Sullam, 2002).

In addition to antigenic differences, serotype III GBS strains also have been classified into four distinct lineages, designated RDP types III-1, -2, -3 and -4, based on HindIII and Sse83871 restriction digest patterns (RDPs) of chromosomal DNA (Takahashi et al., 1998). A multilocus sequence typing (MLST) system has also been developed that categorizes GBS strains based on the combination of alleles of seven housekeeping genes (Jones et al., 2003). Comparison of these two typing methods has shown that RDP III-3 strains correspond to the ST-17 clonal complex lineage. Over $90 \%$ of serotype III invasive neonatal isolates have been identified as RDP III-3, suggesting that this may represent a more virulent lineage (Takahashi et al., 1998). Several investigators have now also reported that ST-17 lineage strains are significantly associated with invasive disease in neonates (Jones et al., 2003; Luan et al., 2005; Bisharat et al., 2004). In this report, it is shown that $\varepsilon$ represents a unique, cell surface-localized, antigenic marker that, in association with the previously identified $\delta$ antigen, distinguishes RDP III-3/ST-17 strains from other GBS. In addition, $\delta / \varepsilon$-positive RDP III- 3 strains that contain $s r r-2$ in the context of the variant secY2/A2 locus are markedly more virulent and demonstrate significantly lower $\mathrm{LD}_{90}$ values in a murine neonatal sepsis model than serotype III GBS that contain srr-1.

\section{METHODS}

Bacterial strains and growth conditions. GBS strains used in this study are listed in Table 1. Strains DL797, DL769, DL771, DL686, DL775, DL1104, DL785 and DL700 were clinical isolates kindly provided by Dr Daniel Lim from the University of South
Florida, Tampa, FL, USA. GBS strains representing RDP III types 1-4 were isolated from vaginal swabs, blood or cerebrospinal fluid, as described previously (Takahashi et al., 1998). Strains COH1 and COH1-13 were kindly provided by Dr Craig Rubens of the University of Washington and Children's Hospital and Regional Medical Center, Seattle, WA, USA. Strain COH1 was isolated from a septic infant (Martin et al., 1988). Strain COH1-13 is an acapsular derivative of COH1 (Rubens \& Heggen, 1988). Strain NEM316 (serotype III, RDP III-1) is an isolate from an infected infant (Glaser et al., 2002), and was obtained from the American Type Culture Collection (ATCC 12403). All streptococci were grown to late-exponential phase in Todd-Hewitt broth (THB) (Becton Dickinson) at $37^{\circ} \mathrm{C}$ without shaking. Escherichia coli strain TOP10 was grown in LuriaBertani (LB) broth at $37^{\circ} \mathrm{C}$ with shaking.

MLST. Internal fragments (400-500 bp) of seven different housekeeping genes were amplified by PCR and sequenced as described by Jones et al. (2003). Sequences were assembled and analysed with the Staden suite of computer programs (Staden, 1996). For each locus, every different sequence was assigned an allele number. Each isolate was assigned a sequence type (ST) based on the seven integers constituting its allelic profile. The sequences of all alleles and the composition of the STs identified in this study are available at http:// pubmlst.org/sagalactiae.

Generation of polyclonal anti-J48 whole-cell antiserum. Rabbit antiserum was produced in a New Zealand white rabbit against stationary-phase cells of GBS strain J48, killed by treatment at $4{ }^{\circ} \mathrm{C}$ overnight with $4 \%$ formalin in $0.85 \%$ saline. Density was adjusted to $\mathrm{OD}_{660}=0.4$ in $0.85 \%$ saline and the rabbit was immunized intravenously with $0.5 \mathrm{ml}$ whole cell suspension three times per week for 1 week, then with $1 \mathrm{ml}$ three times per week for 3 weeks, rested for 3 weeks, and finally with $1 \mathrm{ml}$ three times per week for 2 weeks. The rabbit was rested for 2 weeks, exsanguinated by cardiac puncture under anaesthesia and serum was stored at $-20^{\circ} \mathrm{C}$. Immunization was conducted in accordance with the University of Florida Institutional Animal Care and Use Committee.

Identification of $\varepsilon$ by two-stage radioimmunoassay (RIA). A two-stage RIA was performed as described previously (Brady et al., 1988) using anti-J48 antiserum adsorbed as described below $(1: 1000)$. All assays were performed in duplicate with less than $5 \%$ variation observed between replicate samples. Reactivity of each strain with normal rabbit antiserum was tested as a negative control.

Generation of $\boldsymbol{\varepsilon}$-specific antiserum. To remove antibodies reactive with known GBS antigens, including the group B carbohydrate, serotype III capsular polysaccharide, protein Rib and the $\delta$ antigen, the anti-J48 whole-cell antiserum was exhaustively adsorbed with GBS strain DL700 (serotype III, Rib-positive) followed by strain A909 (serotype Ic/ $\alpha \beta \gamma \delta$ ). Adsorption was performed at a ratio of $100 \mu \mathrm{l}$ antiserum to $10^{9}$ c.f.u. PBS-washed cells with rotation endover-end at $4{ }^{\circ} \mathrm{C}$ for $1 \mathrm{~h}$, and repeated until reactivity against the adsorbing strain, as evaluated by ELISA, was eliminated. The resulting adsorbed polyclonal rabbit antiserum was reactive with strain J48, but not with strain DL700 or A909. The residual antigenic reactivity was designated $\varepsilon$ and this adsorbed reagent was used to detect the $\varepsilon$ antigen in subsequent experiments.

ELISA to evaluate $\varepsilon$ expression. Costar High Binding plates (Corning) were coated with $\sim 10^{7}$ c.f.u. of representative RDP III-1, $-2,-3$ and -4 GBS strains, blocked with PBS containing $0.03 \%$ Tween 20 , reacted with adsorbed anti- $\varepsilon$-specific antiserum $(1: 100)$ followed by affinity-purified, horseradish peroxidase (HRP)-labelled, goat anti-rabbit secondary antibody $(1: 1000)$ (MP Biomedicals), developed with $0.4 \mathrm{mg} \mathrm{ml}^{-1} o$-phenylenediamine (OPD) in $0 \cdot 1 \mathrm{M}$ citric acid $/ 0 \cdot 2 \mathrm{M}$ sodium phosphate buffer, $\mathrm{pH} 4 \cdot 5$, with $0.03 \%$ hydrogen peroxide, and absorbance was read at $450 \mathrm{~nm}$. Control 
Table 1. Bacterial strains

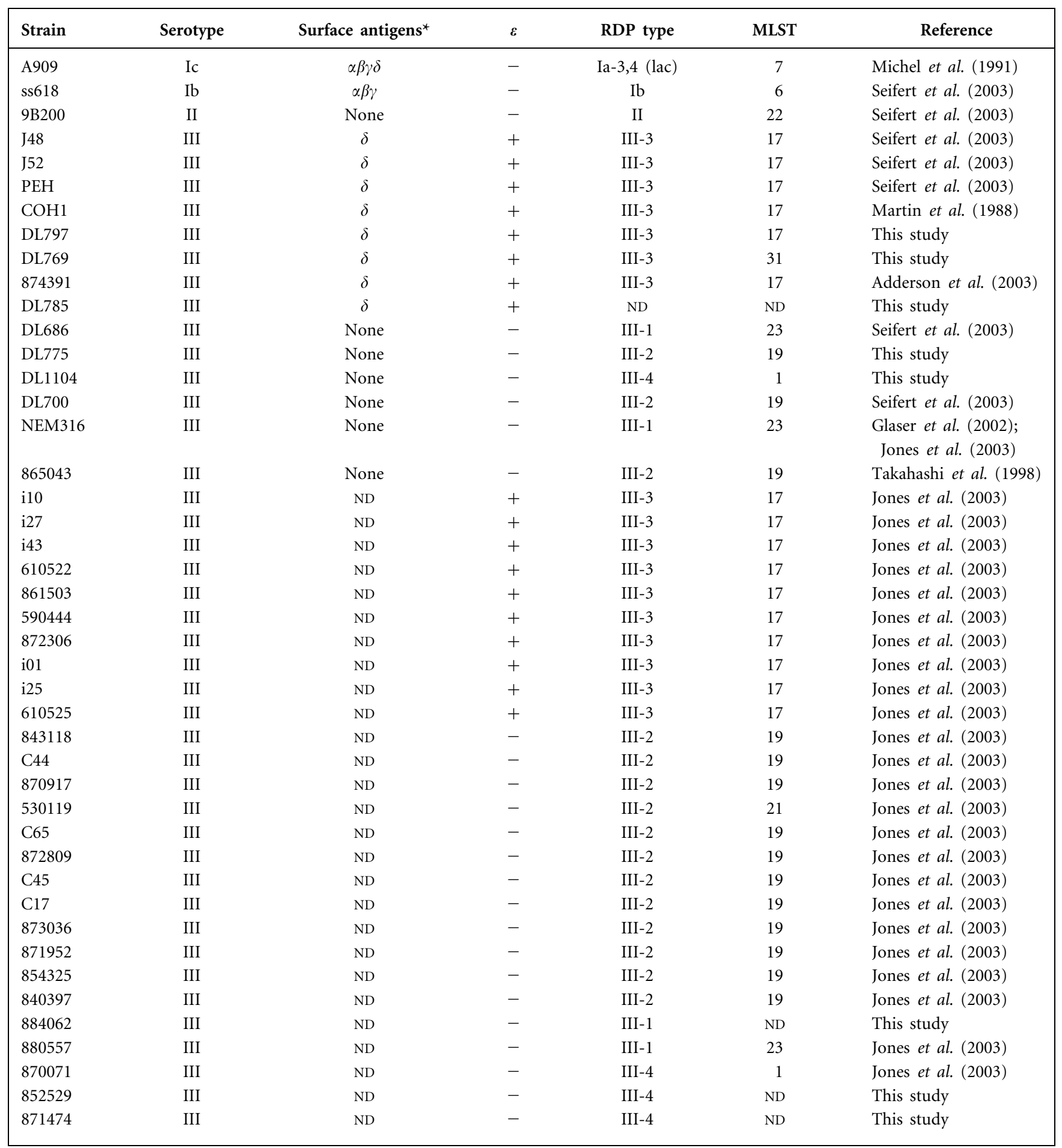

ND, Not determined.

${ }^{\star}$ Surface antigens reactive with c-protein typing serum.

wells were incubated with secondary antibody alone. GBS were considered positive for $\varepsilon$ expression if reactivity with the test antiserum was at least twofold greater than that of the background control. All assays were performed in duplicate with less than $5 \%$ variation observed between replicate samples.
Extraction of $\varepsilon$, anion-exchange chromatography, competition ELISA and Western immunoblot analysis. Cellular extracts were prepared by sonicating $4 \mathrm{~g}$ (wet weight) GBS strains $\mathrm{J} 48$ or DL700 in $4 \mathrm{ml} 20 \mathrm{mM}$ Tris/ $\mathrm{HCl}, \mathrm{pH} 8 \cdot 0$, with $4 \mathrm{~g}$ P-0080 glass beads (Potter's Industries) three times for $30 \mathrm{~s}$ each on ice with a 
Sonic 300 Dismembrator (ARTEK Systems). Glass beads and bacterial debris were removed by centrifugation at $10000 \mathrm{~g}$ for $5 \mathrm{~min}$ followed by centrifugation in a Beckman L7-55 ultracentrifuge (Beckman Coulter) at $100000 \mathrm{~g}$ for $2 \mathrm{~h}$ to remove wall-membrane complexes. Supernatants were filtered through $0 \cdot 2 \mu \mathrm{m}$ pore-size Acrodiscs (Gelman Sciences) and diluted $1: 3$ in $20 \mathrm{mM}$ Tris/ $\mathrm{HCl}$, $\mathrm{pH} 8 \cdot 0$. Extracts were loaded onto a UNO-Q1 (Bio-Rad) anionexchange column and bound molecules were eluted with $0 \cdot 1 \mathrm{M}$ $\mathrm{NaCl}$ in $20 \mathrm{mM}$ Tris/ $\mathrm{HCl}, \mathrm{pH} 8 \cdot 0$, in $0.05 \mathrm{M} \mathrm{NaCl}$ stepwise increments. A competition ELISA was used to identify the $\varepsilon$ antigen in the column fractions. Microtitre plates were coated with $\sim 10^{7}$ c.f.u. per well of strain J48 whole cells. Test wells were incubated with $100 \mu \mathrm{l}$ individual fractions and $100 \mu \mathrm{l}$ adsorbed anti- $\varepsilon$-specific rabbit antiserum $(1: 100)$, followed by HRP-labelled goat anti-rabbit conjugate $(1: 1000)$ (MP Biomedicals) and development with OPD as described above. Percentage inhibition of anti- $\varepsilon$ binding was determined by comparing absorbance values of test wells with control wells containing column buffer only. Column fraction 14 from strain $\mathrm{J} 48$ that contained $\varepsilon$ as determined by competition ELISA, and the corresponding fraction from strain DL700 (serotype III), were evaluated by $7 \cdot 5 \%$ SDS-PAGE and Western immunoblotting (Protran nitrocellulose; Schleicher \& Schuell) with anti- $\varepsilon$-specific antiserum $(1: 100)$ followed by HRP-conjugated goat anti-rabbit IgG $(1: 1000)$ and development with ECL detection reagents (Amersham Biosciences-GE Healthcare).

Elution of $\varepsilon$-containing material from SDS-polyacrylamide gels and composition analysis. One millilitre $\left(1.6 \mathrm{mg} \mathrm{ml}^{-1}\right)$ of sonic extracts of strains J48 and DL700 was separated on multiple $1.5 \mathrm{~mm}$ thick $7.5 \%$ preparatory SDS-polyacrylamide gels $(8.6 \times 6.8 \mathrm{~cm})$. A $2 \mathrm{~mm}$ gel-slice corresponding to the region predicted to contain the $\varepsilon$ antigen, determined by comparative Western immunoblot analysis of the strains J48 and DL700 anion exchange column fractions, was excised from each gel, finely minced with a razor blade and eluted with $500 \mu \mathrm{l} 50 \mathrm{mM}$ ammonium bicarbonate, $\mathrm{pH} 7 \cdot 4$, and $1 \%$ SDS for $2 \mathrm{~h}$ with rocking at $37^{\circ} \mathrm{C}$. Eluted materials were evaluated by Western immunoblots reacted with anti- $\varepsilon$ (1:100), anti- $\delta$ (Brady et al., 1988) $(1: 500)$ or anti-GBS serotype III (Accurate Chemical and Scientific Corporation) (1:1000) antisera, followed by HRP-conjugated goat anti-rabbit IgG ( $\mathrm{H}$ and $\mathrm{L}$ chains) $(1: 1000)$ and development with ECL detection reagents. The eluted materials were also tested for the presence of group B carbohydrate by latex agglutination (Phadabact, Boule Diagnostics, Huddinge, Sweden). Material present in samples from each strain was analysed for amino acid composition by the Interdisciplinary Center for Biotechnology Research (ICBR), University of Florida, Gainesville, FL, USA, and for carbohydrate content by the Complex Carbohydrate Research Center, University of Georgia, Athens, GA, USA.

Cloning, expression and Western immunoblot analysis of recombinant Srr-2. Previously, a genomic phage library of GBS strain 874391 (Bohnsack et al., 2002) had been screened with the RDP type III-3 specific probe, DY-3 (Bohnsack et al., 2001). An 8816 bp genomic DNA fragment that hybridized with this probe was purified and cloned (Adderson et al., 2003). The clone included an ORF of $3.6 \mathrm{~kb}$ predicted to encode a serine-rich protein that was subsequently designated $s r-2$ for serine-rich repeat variant 2 to dif-

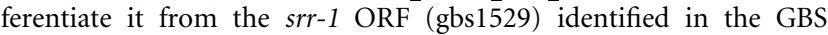
NEM316 genomic sequence (Glaser et al., 2002). The srr-2 gene from the RDP type III-3 GBS strain J48 was PCR-amplified from genomic DNA (Nagano et al., 1991) using primers KS51 (5'-tcacgcaaagttcgagttaaaa- $\left.3^{\prime}\right)$ and KS53 (5'-cgcagatttagtagctcctaa- $\left.3^{\prime}\right)$ and ligated to the pBAD-TOPO expression vector (Invitrogen), resulting in pKS60. Expression of recombinant Srr-2 was induced by addition of 10 -fold increasing amounts of $\mathrm{L}$-arabinose $(0 \cdot 0002-2 \%)$ to midexponential phase E. coli TOP10 cells $\left(\mathrm{OD}_{600}=0 \cdot 5\right)$ harbouring pKS60. After $4 \mathrm{~h}$, cells were harvested and boiled in SDS/sample buffer $(62.5 \mathrm{mM}$ Tris/HCl, pH 6.8, $10 \%$ glycerol, $2 \%$ SDS, $0 \cdot 02 \%$ bromophenol blue) and samples analysed by Western immunoblotting. One membrane was incubated with mouse anti-V5 monoclonal antibody (Invitrogen) (1:5000) followed by HRP-conjugated goat anti-mouse IgG (H and L chain specific) $(1: 1000)$ and developed with 4-chloro-1-naphthol solution [7 $\mathrm{ml} \mathrm{PBS,} 1 \mathrm{ml}$ methanol containing $3 \mathrm{mg}$ 4-chloro-1-naphthol (Sigma) with $0.03 \%$ hydrogen peroxide]. A replicate membrane was incubated with anti- $\varepsilon$ specific antiserum $(1: 100)$ followed by HRP-conjugated goat anti-rabbit $\operatorname{IgG}(1: 1000)$ and developed with ECL detection reagents.

Southern analysis of srr genes. DNA hybridization was performed by the method of Southern (Sambrook et al., 1989). Chromosomal DNA was isolated as described by Nagano et al. (1991) and further purified on $\mathrm{CsCl}$ gradients. Genomic DNA was digested with EcoRV (Promega), separated by electrophoresis on replicate $0.7 \%$ agarose gels, and transferred to nylon membranes (Roche Applied Science) by capillary blotting. One membrane was probed with srr-1 that had been PCR-amplified from strain DL700 genomic DNA using primers KS13 (5' -atgtcccaaaagacttttggc- $\left.3^{\prime}\right)$ and KS14 (5' cgtcccaaaagggttgcaccagtca- $3^{\prime}$ ) derived from the genomic sequence of srr-1 (gbs1529) from strain NEM316 (Glaser et al., 2002). The other membrane was probed with $s r r-2$ that had been PCR-amplified from strain J48 genomic DNA as described in the previous section. Both probes were labelled during PCR-amplification with DIG-11-dUTP (Roche Applied Science). Hybridization was at $42^{\circ} \mathrm{C}$ for $16 \mathrm{~h}$ and the blots were developed according to the manufacturer's instructions. Negative and positive controls included pPC185 (Kremer et al., 2001) and unlabelled PCR-amplified srr-1 or srr-2, respectively.

DNA sequencing. Chromosomal DNA from strain J48 was prepared as described in the previous section and primer walking was used to obtain sequences of genes upstream and downstream of srr-2. DNA sequencing was performed by the DNA Sequencing Facility at Iowa State University (Ames, IA, USA) and the DNA Sequencing Facility of the Interdisciplinary Center for Biotechnology Research at the University of Florida, Gainesville, FL, USA. Sequences were compiled at the University of Florida and analysed with MacVector version 8 (Accelrys) to find and translate ORFs. Translated ORFs were subjected to BLASTp analysis (http://www.ncbi.nlm.nih.gov) to identify protein homologues.

Evaluation of $\mathbf{L D}_{\mathbf{9 0}}$. A neonatal mouse model of infection (Rodewald et al., 1992) was used to compare the $\mathrm{LD}_{90}$ values of serotype $\mathrm{III} / \delta \varepsilon_{-}$ positive and serotype III/ $\delta \varepsilon$-negative strains. Offspring (8-14) from one dam of timed-pregnant, CD-1 virus antibody-free female mice (Charles River Laboratories) were each inoculated intraperitoneally $24-48 \mathrm{~h}$ after birth with a given challenge dose $\left(10^{2}-10^{10}\right.$ c.f.u. $)$ diluted in $100 \mu \mathrm{l}$ THB. Deaths were recorded for $72 \mathrm{~h}$ post-inoculation. $\mathrm{LD}_{90}$ values were determined by the Reed-Muench method (Reed \& Muench, 1938). The $\mathrm{LD}_{90}$ values were grouped according to $\delta / \varepsilon$ expression and compared using a two-sample $t$ test of log-transformed data. Animal experiments were conducted in accordance with the University of Florida Institutional Animal Care and Use Committee.

\section{RESULTS}

\section{Identificaton of $\varepsilon$ antigen}

The $\delta$ antigen was initially recognized on the surface of a subset of serotype III strains following exhaustive adsorption of anti-c-protein typing antiserum with non-serotype III strains of GBS that expressed $\alpha, \beta$ and $\gamma$ antigens (Brady et al., 1988). The GBS strains analysed in this study and their surface expression of the $\alpha, \beta, \gamma$ and $\delta$ antigens are indicated in Table 1. In the current study, formalin-fixed 
serotype III $/ \delta$-positive strain J48 whole cells were used as an immunogen with the goal of generating a polyclonal reagent containing anti- $\delta$ antibodies, but lacking anti- $\alpha, \beta$ and $\gamma$ antibodies. The antiserum was exhaustively adsorbed with the serotype III/ $\delta$-negative GBS strain DL700 to eliminate antibodies against other cell-surface-localized, non- $\delta$ antigens, including protein Rib, the Group B carbohydrate and the serotype III capsular polysaccharide. To evaluate the relationship between the $\delta$ antigen present on serotype III GBS and that originally detected on GBS serotype Ic strain A909, the immunizing strain used to generate the c-protein typing serum, the anti-J48 $\delta$-reactive reagent described above was further adsorbed with A909 whole cells and reacted with serotype III/ $\delta$-positive and III/ $\delta$-negative strains, as well as with strain A909, using a two-stage RIA (Fig. 1). Prior to adsorption with A909, the anti-J48-derived $\delta$-reactive antiserum reacted with A909 and those serotype III strains previously identified as $\delta$-positive, thus replicating the results obtained using the original $\delta$-specific reagent derived from the anti-c-protein antiserum. However, following adsorption of the strain J48-derived anti- $\delta$-reactive reagent with A909, residual reactivity remained with all of the serotype III $\delta$-positive strains, even though reactivity with the $\delta$-positive A909 strain had been completely eliminated. This indicates that an additional antigen is coexpressed with $\delta$ on serotype III strains and that this antigen is absent from strain A909. The newly identified antigen was designated $\varepsilon$, and the anti-J48 antiserum that had been exhaustively adsorbed with strains DL700 and A909 was used as the $\varepsilon$-specific antiserum in subsequent experiments. Over 30 serotype III $/ \delta$-positive strains have been tested and found to express $\varepsilon$. To date, we have found no serotype III strain that expresses $\varepsilon$ in the absence of $\delta$ or vice versa (data not shown).

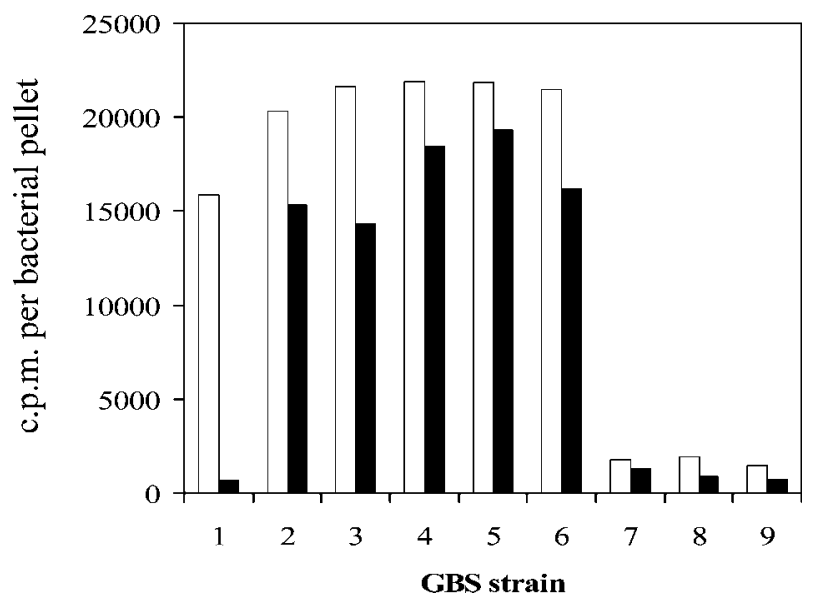

Fig. 1. Identification of $\varepsilon$ antigen by RIA. GBS were reacted with anti-J48 antiserum adsorbed with DL700 (white bars) or DL700 and A909 (solid bars). Lanes 1-9 correspond to GBS strains A909, J48, PEH, DL797, DL769, DL771, DL686, DL775 and DL700.

\section{Extraction and partial characterization of the $\varepsilon$ antigen}

Sonic extracts of GBS strains J48 and DL700 were prepared and subjected to anion-exchange chromatography in parallel. A competition ELISA was used to identify $\varepsilon$ in individual anion-exchange column fractions. Material contained in fractions $13-17$ (eluted at $0 \cdot 2 \mathrm{M} \mathrm{NaCl}$ ) from the J48 sample inhibited anti- $\varepsilon$-specific antiserum binding to J48 whole cells to a greater degree than other column fractions or any column fraction from strain DL700, indicating the enrichment of $\varepsilon$ in these fractions (Fig. 2A). These fractions also contained other surface antigens, including the $\delta$ antigen and serotype III polysaccharides, identified by competition ELISA and Western immunoblotting, as well as the group B carbohydrate identified by latex agglutination (data not shown). Material from strain J48 column fraction 14 and the corresponding column fraction from the negative control strain DL700 were analysed by SDS-PAGE and Western immunoblotting with anti- $\varepsilon$ antiserum. While SDS-PAGE profiles of fractions 14 derived from J48 and DL700 appeared identical (data not shown), a prominent band migrating at $>250 \mathrm{kDa}$ was identified by Western immunoblotting of the J48 sample (Fig. 2B, lane 2, arrow) but not the DL700 sample (Fig. 2B, lane 1). This band did not stain with Coomassie brilliant blue, silver, or colloidal gold protein stains (data not shown). To gain some insight into the nature of the $\varepsilon$ antigen, material in the $>250 \mathrm{kDa}$ molecular mass range was eluted in parallel from SDSpolyacrylamide preparatory gels of both the strain J48 and DL700 sonic extracts. The material eluted from the J48, but not the DL700, gel inhibited anti- $\varepsilon$ reactivity with J48 whole cells by competition ELISA, confirming the presence of $\varepsilon$ in strain J48 and its absence in DL700 (data not shown). Anti- $\varepsilon$ antiserum reacted with the high-molecular-mass gel-eluted material from strain J48 but not from DL700 (Fig. 2C, panel a). Neither anti- $\delta$ nor anti-serotype III antisera reacted with the material eluted from SDS-polyacrylamide gels from either strain (Fig. 2C, panels b and c); however, the gelpurified material from each strain still tested positive by latex agglutination for the group $\mathrm{B}$, but not $\mathrm{A}, \mathrm{C}, \mathrm{D}$ or G group antigens (data not shown). Carbohydrate composition analysis of the $\sim 250 \mathrm{kDa}$ eluted material from both J48 and DL700 demonstrated the presence of rhamnose, mannose, galactose and glucose in a molar ratio of $4: 1: 1: 6$. The group B antigen is composed of rhamnose, $\mathrm{N}$-acetylglucosamine, galactose and glucitol (Michon et al., 1988); therefore, it is likely that a component of the group antigen was present in the samples from both strains. Amino acid composition of gel-eluted materials from both J48 and DL700 indicated the presence of either a glycine- or serine-rich protein (data not shown).

\section{Evaluation of $\varepsilon$ expression by RDP III type 1-4 strains and correlation with MLST type}

Serotype III GBS are categorized into four distinct lineages based on HindIII and Sse83871 RDPs of chromosomal DNA (Takahashi et al., 1998). To determine if there was a 
(A)

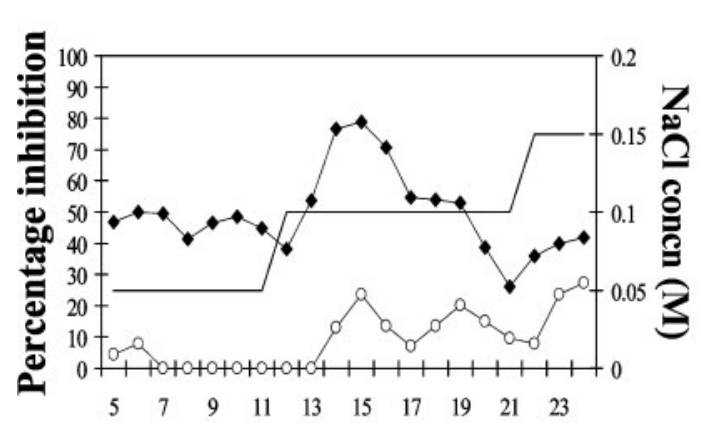

Column fraction
(B)

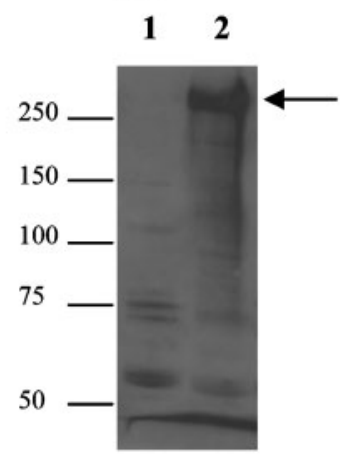

(C)

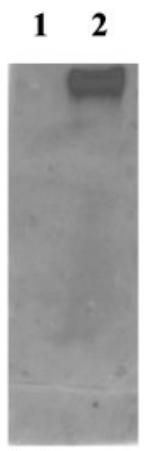

(a)

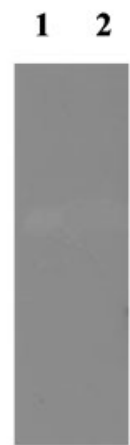

(b)

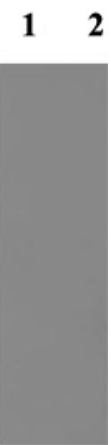

(c)

Fig. 2. Detection of $\varepsilon$ by competition ELISA and Western immunoblotting. (A) Column fractions from anion-exchange chromatography of strain $J 48(\checkmark)$ and DL700 $(\bigcirc)$ sonic extracts were tested for inhibition of binding of anti- $\varepsilon$-reactive antiserum to $\mathrm{J} 48$ whole cells by competition ELISA. Stepwise elution of bound material with $\mathrm{NaCl}$ is indicated. (B) Western blot of column fraction 14 from strain DL700 (lane 1) or J48 (lane 2) reacted with anti- $\varepsilon$-reactive antiserum. (C) Western blot of $>250 \mathrm{kDa}$ material eluted from strain DL700 (lane 1) or J48 (lane 2) reacted with anti- $\varepsilon$ (a), anti- $\delta$ (b) or anti-serotype III (c) antisera. Migration of molecular mass markers is indicated in $\mathrm{kDa}$.

correlation between $\varepsilon$ expression and RDP type, a panel of previously typed GBS strains representing RDP III-1, -2, -3 and -4 (Takahashi et al., 1998; Jones et al., 2003) was tested by ELISA using anti- $\varepsilon$ antiserum. All RDP III- $1(n=4)$, III-2 $(n=15)$ and III-4 $(n=4)$ strains tested were negative for $\varepsilon$ expression, while all RDP III-3 strains $(n=17)$ were $\varepsilon$ positive. These results indicate that among serotype III GBS, $\varepsilon$ expression represents an antigenic marker for the RDP III3 lineage. As stated above, to date we have found no serotype III strain that expresses $\varepsilon$ without $\delta$ or vice versa. No non-serotype III GBS have been identified that express $\varepsilon$ and strain A909 represents the only known exception of $\delta$ expression by a non-serotype III strain.

Because of the reported association of RDP III-3 GBS with ST-17 (Jones et al., 2003), additional MLST of serotype III $\varepsilon$ positive and $\varepsilon$-negative strains was performed. These results are summarized in Table 1 . As expected, all $\varepsilon$-positive RDP III-3 strains $(n=17)$ either were ST-17 $(n=16)$ or were of the ST-17 clonal complex lineage, ST-31 $(n=1)$, which differs from ST-17 at only one allele (Davies et al., 2004). None of the non-RDP III- 3 strains tested $(n=23)$ was found to be ST-17 or to belong to the ST-17 clonal complex.

\section{Identification of a novel GBS Srr protein}

Bohnsack et al. (2002) previously used genomic subtractive hybridization to identify DNA sequences unique to RDP III-3 strains. One resulting clone from the RDP III-3 GBS strain 874391 included a 3618 bp ORF, designated herein as $s r r-2$, predicted to encode a high-molecular-mass protein $(125 \mathrm{kDa})$ containing a highly repetitive serine- $(36 \%)$ and aspartate-rich (12\%) region. The predicted protein, Srr-2, has a signal peptide and LPXTG motif common to this family of cell-wall-anchored proteins (Fischetti et al., 1990). Srr-2 has only limited homology ( $<20 \%$ identity) with the predicted Srr protein identified in the sequenced genomes of GBS strains NEM316 (serotype III, RDP III-1), A909 (serotype Ic) and 2603V/R (serotype V) [Glaser et al. (2002), GenBank accession no. NC_004128; Tettelin et al. (2002)], and designated herein as Srr-1.

Schematic representations of GBS Srr-1 and Srr-2, and serine-rich proteins from other streptococci, are shown in Fig. 3. Srrs from GBS and other streptococci are relatively large, with $\sim 50$ aa signal sequences, a small $\mathrm{N}$-terminal Srr region (RI) located between two non-repeat regions $(\mathrm{N})$, a large Srr region (RII) that comprises a substantial portion of the entire protein, and an LPXTG-wall-anchor region (A) near the $\mathrm{C}$ terminus. The predicted secondary structure of the Srr proteins from GBS is similar to that of Srr proteins from other streptococcal species (Wu et al., 1998; Bensing \& Sullam, 2002; Takahashi et al., 2002). The amino acids that alternate with serine in the repeat regions of Srr proteins vary among individual proteins. Srr-1s from the three sequenced GBS strains share $89-100 \%$ identity prior to the RII region, with only a length difference and minor substitutions observed among the RII sequences themselves. In contrast, Srr-1 and Srr- 2 sequences demonstrate no more than $36 \%$ identity prior to the RII region. The predominant amino acid residues that alternate with serine within RII of Srr- 1 are alanine, threonine and methionine, whereas in Srr2 they are valine, isoleucine, threonine, asparagine, glutamic acid and serine. The predicted amino acid sequences of Srr2 from strains J48 and 874391 are nearly identical to one another except that the RII region from 874391 contains an additional 100 aa. 


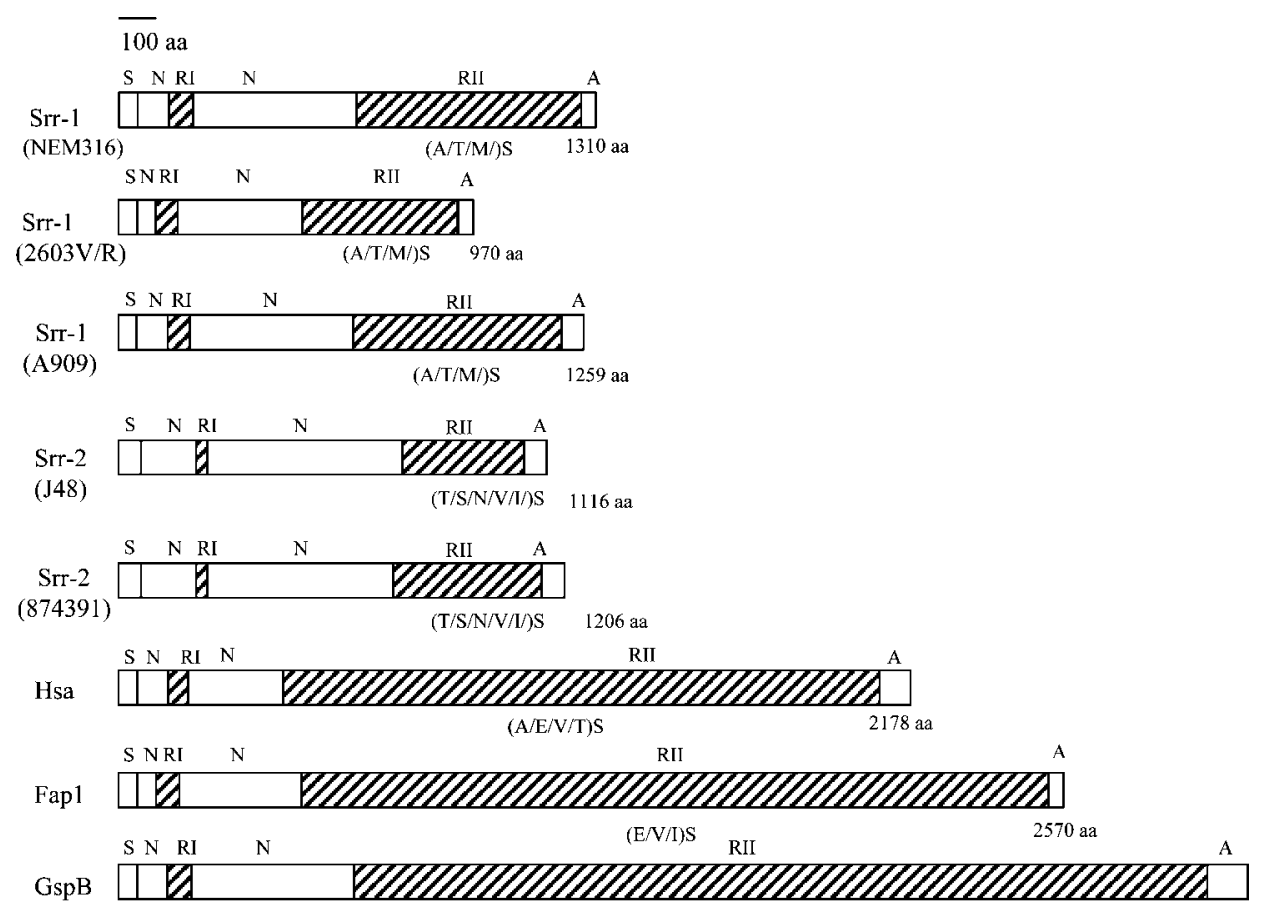

$(\mathrm{A} / \mathrm{E} / \mathrm{V} / \mathrm{T}) \mathrm{S}$

3072 aа

Fig. 3. Schematic representation of streptococcal Srr proteins. Srr-1 is from GBS strains NEM316, 2603V/R and A909; Srr2 is from GBS strains $\mathrm{J} 48$ and 874391; Hsa and GspB are from S. gordonii strains Challis and M99 (Bensing \& Sullam, 2002; Takahashi et al., 2002), respectively; and Fap1 is from S. parasanguinis strain FW213 (Wu et al., 1998). S, signal sequence; N, non-repeat region; RI, small repeat region I; RII, large repeat region II; A, cell wall sorting signal; (X)S, di-peptide repeat motif. The predominant amino acid residues that alternate with serine within the Rll regions are indicated in parentheses. Bar, 100 aa.

\section{Identification of srr-2 in $\varepsilon$-positive GBS}

Southern hybridization was used to determine the relationship between $\varepsilon$ expression and the presence of either $s r-1$ or srr-2 in representative GBS strains. DIG-labelled srr-1 PCRamplified from strain DL700 genomic DNA hybridized with all $\varepsilon$-negative strains (Fig. 4, Panel A, lanes 1-3, 9 and 10), while labelled srr-2 PCR-amplified from strain J48 genomic DNA hybridized with all $\varepsilon$-positive strains (Fig. 4, Panel B, lanes $4-8$ ). This suggests that $\varepsilon$-positive RDP III-3 strains possess $s r r-2$. Conversely, non-RDP III-3 strains that do not express $\varepsilon$ possess $s r r-1$.

\section{Comparison of secY2/A2 loci in GBS strains}

The sequenced genomes from GBS strains NEM316, A909 and $2603 \mathrm{~V} / \mathrm{R}$ indicate that $s r r-1$ is located in a putative operon similar to that of Streptococcus gordonii, named $\sec Y 2 / A 2$, due to the presence of the genes secA2 and secY2 which are dedicated to the export of the Srr protein GspB, and which bear homology to $\sec A$ and $\sec Y$ (Bensing \& Sullam, 2002). To determine whether srr-2 from strain J48 was located in a similar secY2/A2 locus, genes upstream and downstream of $s r-2$ were sequenced and analysed for the presence of ORFs. The homology of translated amino

\section{(A)}

$\begin{array}{lllllllllllll}1 & 2 & 3 & 4 & 5 & 6 & 7 & 8 & 9 & 10 & 11 & 12\end{array}$

(B)

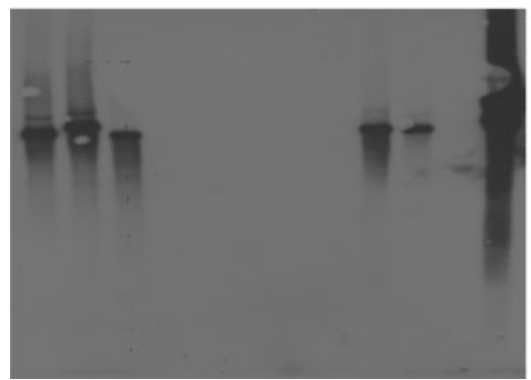

Fig. 4. Detection of $s r r-1$ and $s r r-2$ by Southern hybridization. DIG-labelled srr-1 PCR-amplified from strain DL700 (A) and srr2 from strain $\mathrm{J48}$ (B) were reacted with EcoRV-digested chromosomal DNA from GBS strains A909, ss618, 9B200, J48, J52, $\mathrm{PEH}, \mathrm{COH} 1, \mathrm{COH} 1-13, \mathrm{DL} 700$ and DL1104 (lanes 1-10); pPC185 (Kremer et al., 2001) (negative control; lane 11) and PCR-amplified srr-1 or srr-2 (positive control; lane 12). 
acid sequences was compared to that of other proteins entered into the GenBank database using the BLASTP program (http://www.ncbi.nlm.nih.gov:80/blast/) (Fig. 5). In strain $\mathrm{J} 48$, a $\sec Y 2$ gene homologue is located immediately downstream of srr-2 and is followed by asp1-3, secA2, gtf A and $g t f B$, gene homologues similar to those contained within the secY2/A2 loci of other streptococcal and staphylococcal species (Takamatsu et al., 2004a, b). Interestingly, the srr-2containing locus of strain $\mathrm{J} 48$ has an organization more similar to that of staphylococci, in that the $\sec Y 2$ gene lies only 113 nt downstream of the srr-2 gene. In GBS strains NEM316 (Glaser et al., 2002), A909 (Tettelin et al., 2005) and $2603 \mathrm{~V} / \mathrm{R}$ (Tettelin et al., 2002), srr-1 and secY2 are separated by approximately $12 \mathrm{~kb}$ of DNA that includes a homologue of streptococcal nss and four to five putative glycosyltransferase $(g l y)$ genes. In strain $2603 \mathrm{~V} / \mathrm{R}$, a vestige of a transposase gene replaces gly3. In strain J48, nss and a single gly gene are located at the $3^{\prime}$ end of the locus and lie downstream of $g t f A$ and $g t f B$.

\section{Anti- $\varepsilon$ antibody reactivity with recombinant Srr-2}

To determine if Srr-2 itself was recognized by the anti- $\varepsilon$ antiserum, srr-2 was PCR-amplified from strain J48 and cloned into the $\mathrm{pBAD}-\mathrm{TOPO}$ expression vector. Expression of Srr-2 was induced in E. coli with increasing concentrations of arabinose, and cell lysates were analysed by Western immunoblotting for the presence of the recombinant protein, using a monoclonal antibody directed against the $\mathrm{V} 5$ epitope tag. A reactive band was detected at $>250 \mathrm{kDa}$
(Fig. 6, Panel A, arrow) that was also recognized by the anti- $\varepsilon$-specific antiserum (Fig. 6, Panel B). Several smaller molecular mass bands were also reactive with the anti- $\varepsilon$ reagent. These presumably represent Srr-2 breakdown products or incompletely translated recombinant protein. Minimal background reactivity was detected in the non-induced, negative control sample (Fig. 6, lane 6). The apparent molecular mass of $>250 \mathrm{kDa}$ is larger than the size predicted for recombinant Srr-2 (125 kDa); however, when the protein was analysed in the presence of $9 \mathrm{M}$ urea, Srr-2 migrated at the predicted size (data not shown). This suggests that the protein may exist as a dimer in the absence of strongly denaturing conditions. This abnormal migration may also be due to the highly repetitive nature of the protein.

\section{Determination of LD $_{90}$ for serotype III $\delta / \varepsilon$-positive and $\delta / \varepsilon$-negative GBS strains}

A large majority (91\%) of serotype III invasive neonatal isolates are of the RDP III-3 type (Takahashi et al., 1998), and Brady et al. (1996) found that serotype III GBS isolated from infants with GBS sepsis expressed $\delta / \varepsilon(83 \cdot 3 \%, n=18)$ more frequently than serotype III isolates from colonized, but healthy, newborns $(58 \cdot 8 \%, n=34)$. LD 90 experiments were conducted to evaluate the lethality of $s r r$-2-containing, $\delta / \varepsilon$-positive, RDP III-3 GBS compared to $\delta / \varepsilon$-negative, nonRDP III-3 serotype III strains using a neonatal mouse model (Rodewald et al., 1992). LD 90 values were notably partitioned into two distinct groups (Fig. 7). RDP III-3,

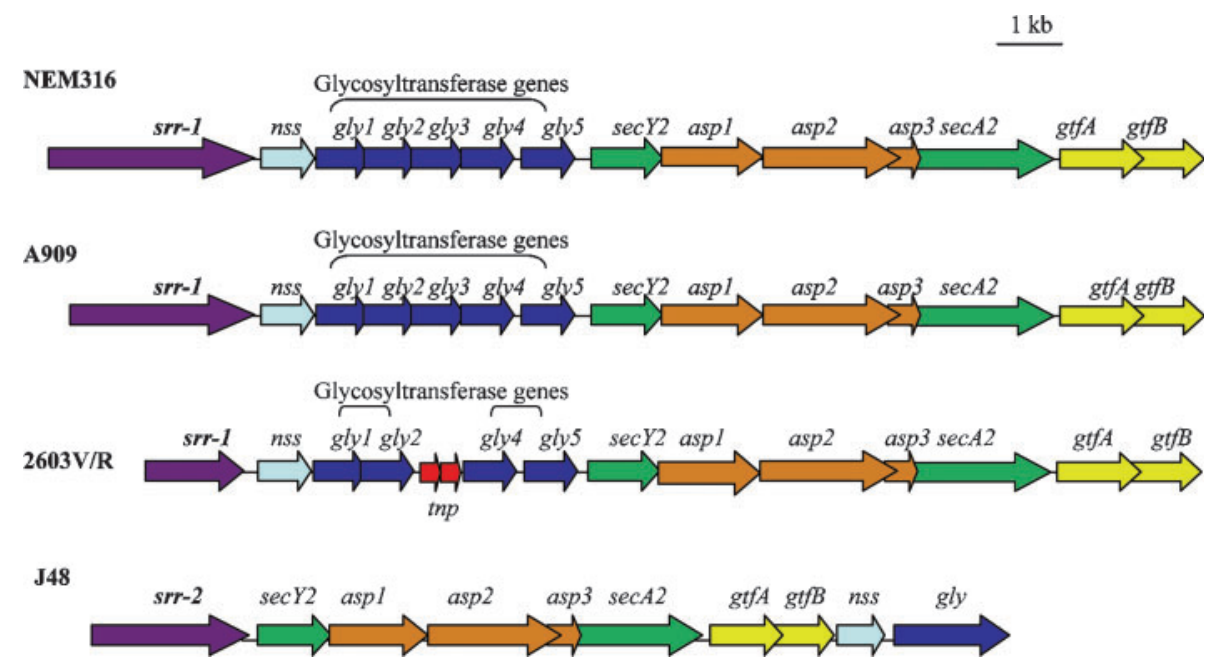

Fig. 5. Schematic representation of GBS secY2/A2 loci containing srr-1 and srr-2. Sequences for GBS strains NEM316, A909 and 2603V/R were retrieved from the NCBI website (http://www.ncbi.nlm.nih.gov) using BLASTP. Chromosomal DNA from strain $\mathrm{J} 48$ was sequenced as part of this study. ORFs were identified, translated and analysed for homologies to genes within other streptococcal and staphylococcal secY2/A2 loci using the MacVector version 8 program (Accelrys). The gene designations srr, secY2, secA2, asp1-3, nss and gly (Takamatsu et al., 2004a), and gtfA and gtfB (previously gtf and orf4) (Takamatsu et al., 2004b) were used to conform to those previously described within the secY2/A2 locus of S. gordonii M99. The two small red arrows in the $2603 \mathrm{~V} / \mathrm{R}$ schematic represent the putative OrfA- and OrfB-encoded transposases of strain IS1381 (tnp) (Takamatsu et al., 2004a). 
(A)

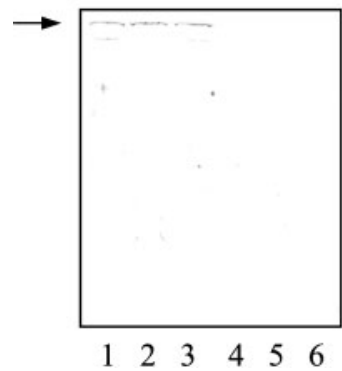

(B)

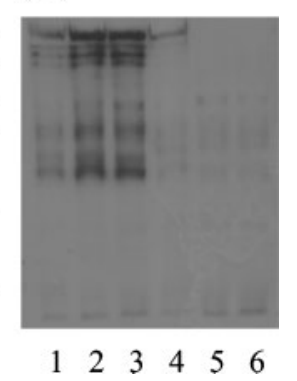

Fig. 6. Western immunoblotting of recombinant Srr-2. Mouse anti-V5 (A) or rabbit anti- $\varepsilon$-specific (B) antibodies were reacted with cell lysates of $E$. coli harbouring pKS60 containing PCRamplified srr-2 from strain J48. Lanes 1-5, induction of recombinant protein expression with 10-fold decreasing amounts of L-arabinose from 2\% (lane 1) to $0.0002 \%$ (lane 5); lane 6, uninduced control. Migration of 250, 150, 100, 75, 50 and $37 \mathrm{kDa}$ molecular mass markers is indicated.

$\delta / \varepsilon$-positive strains demonstrated $\mathrm{LD}_{90}$ values between $4.6 \times 10^{2}$ and $8 \times 10^{3}$ c.f.u., while $\delta / \varepsilon$-negative strains demonstrated significantly higher values between $9 \cdot 8 \times 10^{6}$ and $6 \times 10^{8}$ c.f.u. $(P<0 \cdot 0005)$. This striking difference in $\mathrm{LD}_{90}$ values supports the hypothesis that $\delta / \varepsilon$-positive $\mathrm{RDP}$ III-3 organisms are more virulent than other serotype III GBS strains in neonates.

\section{DISCUSSION}

In this study, a novel immunological reactivity, designated $\varepsilon$, was detected on serotype III GBS that expressed the previously identified $\delta$ antigen (Brady et al., 1988). Analysis of $\geqslant 250 \mathrm{kDa}$ material reactive with anti- $\varepsilon$ antiserum,

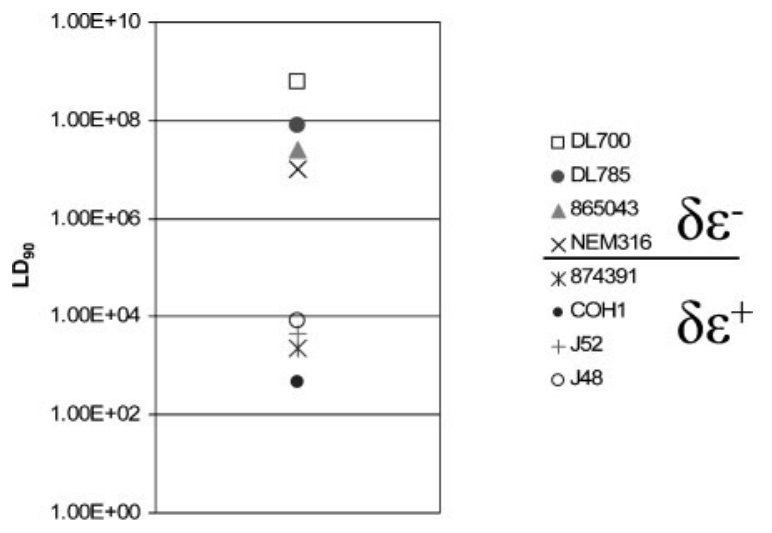

Fig. 7. Comparison of $\mathrm{LD}_{90}$ values. Strains DL700, DL785, 865043 and NEM316 are serotype III, $\delta / \varepsilon$-negative strains, and 874391, COH1, J52 and J48 are RDP III-3 serotype III, $\delta / \varepsilon^{-}$ positive strains $(P<0.0005$ for two sample $t$ test of logtransformed data). present in a sonic extract and separated by anion-exchange chromatography, suggests a protein rich in either glycine or serine. The additional detection of rhamnose, mannose, galactose and glucose is consistent with $\varepsilon$ belonging to a family of high molecular mass, serine-rich, glycoprotein adhesins described for other streptococci and staphylococci (Wu et al., 1998; Wu \& Fives-Taylor, 1999; Takahashi et al., 2002; Bensing et al., 2004; Siboo et al., 2005). Examination of the sequenced genomes of three GBS strains revealed no putative glycine-rich proteins, but did demonstrate the presence of an ORF predicted to encode a protein composed of $\sim 32 \%$ serine. In addition, examination of a previously described clone (Bohnsack et al., 2001), identified using a probe generated by subtractive hybridization of a GBS RDP III-3 strain with an RDP III-2 strain, revealed the presence of an ORF encoding a different Srr protein. This ORF was designated $s r r-2$ to distinguish it from $s r r-1$ contained within the three known GBS genomic sequences. While similar in architecture, comparison of srr-1 and srr-2 showed substantial differences in their primary sequences. In addition, the number of putative glycosyltransferase genes and organization of the secY2/A2 loci containing srr- 1 and srr-2 were different.

Streptococcus agalactiae is known to harbour at least five mobile genetic elements, a factor presumably involved in the genomic and phenotypic plasticity of this organism (HéryArnaud et al., 2005). Analysis of eight GBS genomes, encompassing five serotypes, has revealed a core genome composed of 1811 genes ( $\sim 80 \%$ of each genome) and a variable genome of at least 765 additional genes that are not present in all strains (Maione et al., 2005; Tettelin et al., 2005). In this age of comparative genomics, our results highlight that certain variable genes are associated with more highly virulent organisms and underscore that antigenic characterization is a useful tool, in conjunction with genetic techniques, to identify and group strains with distinguishing characteristics. Interestingly, comparison of the eight sequenced GBS genomes revealed a strain-specific locus within the serotype III GBS strain $\mathrm{COH}-1$ predicted to encode SecA and SecY subunits, three glycosyltransferases and a highly repetitive serine-rich, cell-wall-anchored protein (Tettelin et al., 2005). Strain $\mathrm{COH}-1$ was evaluated as part of the current study and is a $\delta / \varepsilon$-positive, RDP III- 3 , ST-17 strain.

An absolute correlation was demonstrated between $\delta / \varepsilon$ expression, RDP III-3 type, ST-17 clonal complex lineage and the presence of $s r r-2$. A murine model of neonatal sepsis was employed to determine the $\mathrm{LD}_{90}$ values for serotype III GBS strains that contain srr-2 compared to srr-1. Notably, the $\mathrm{LD}_{90}$ values of the former group were several orders of magnitude less than the latter group. These results indicate that, in this model system, srr-2-containing serotype III GBS are significantly more virulent than srr-1-containing organisms, and that the cell surface expression of $\delta / \varepsilon$ readily identifies this lineage. Results are consistent with epidemiological observations, as well as with the previous identification 
of a high-virulence clone of serotype III GBS associated with invasive neonatal disease (Musser et al., 1989) that was subsequently identified as an RDP III-3 strain (Fleming et al., 2004). Several studies have reported an association of the GBS ST-17 lineage with invasive disease in neonates (Jones et al., 2003; Luan et al., 2005; Bisharat et al., 2004), although Davies et al. (2004) did not detect an association of MLST type with invasive versus colonizing serotype III GBS isolates. An evaluation of MLST types among 158 isolates collected from neonates and adults strongly suggests that the ST-17 lineage is particularly well adapted to neonates (Luan et al., 2004). Furthermore, Bisharat et al. (2004) have reported that ST-17 complex strains are hyperinvasive in neonates and represent a discrete clonal lineage that has recently arisen from a strain of bovine origin. Our results support the hypothesis that $\delta / \varepsilon$-positive, RDP III-3, ST-17 complex GBS strains represent the same clonal lineage and that GBS strains within this lineage are significantly more lethal than other serotype III organisms in an animal model of neonatal sepsis. Whether pathogenesis is linked directly to the expression of $s r r-2$, or other genes within the srr-2containing locus, is the focus of ongoing work and will require the construction and evaluation of isogenic mutants.

The functions of the GBS Srr proteins are as yet unknown. Other streptococcal Srr proteins have been reported to function as adhesins (Wu et al., 1998; Bensing \& Sullam, 2002; Takahashi et al., 2002). Fap1 from Streptococcus parasanguinis (formerly parasanguis) binds to saliva-coated hydroxyapatite (Wu et al., 1998; Wu \& Fives-Taylor, 1999), and a Fap1-like protein, SrpA of Streptococcus cristatus, is associated with adhesion to heterologous bacterial species from plaque biofilm (Handley et al., 2005). S. gordonii GspB mediates binding to human platelets (Bensing \& Sullam, 2002). S. gordonii strain DL1 contains a gene (hsa) with a deduced amino acid sequence similar to that reported for GspB. The encoded protein, Hsa, mediates binding to $\alpha-2,3-$ linked sialoglycoconjugates and bacterial haemagglutinating activity (Takahashi et al., 2002). It is, as yet, unknown whether the Srr proteins of GBS also act as adhesins and, if so, whether Srr-1 and Srr-2 bind to different substrates.

The streptococcal Srr proteins that have been characterized to date are high-molecular-mass glycoproteins (Wu et al., 1998; Chen et al., 2002; Takahashi et al., 2002; Takamatsu et al., 2004a). GspB from S. gordonii is glycosylated with $\mathrm{N}$-acetylglucosamine, glucose and a minor amount of $\mathrm{N}$ acetylgalactosamine (Bensing et al., 2004). Nss, Gly, GtfA and GtfB function intracellularly and are required for the correct glycosylation of GspB, although the specific enzymic functions of these proteins are unknown (Takamatsu et al., $2004 a, b)$. Homologues of genes encoding these proteins are present within the secY2/A2 loci from both srr-1- and srr2-containing GBS. In S. parasanguinis, Fap1 is associated with rhamnose, glucose, galactose, $N$-acetylglucosamine and $\mathrm{N}$-acetylgalactosamine (Stephenson et al., 2002). Hsa, the sialic acid-binding adhesin from $S$. gordonii, has also been reported to be glycosylated, although the sugars associated with Hsa have not been determined (Takahashi et al., 2004). The cloned product of GBS, srr-2, was recognized by polyclonal anti- $\varepsilon$ antiserum, indicating that this antigenic reactivity consists, at least in part, of a protein component. Anti- $\varepsilon$ reactivity with GBS J48 whole cells, or with antigen contained within J48 cellular extracts, was destroyed by treatment with proteinase $\mathrm{K}$ (data not shown). In addition, reactivity was also notably diminished by treatment with sodium metaperiodate (data not shown). These results are consistent with the complete native streptococcal $\varepsilon$ antigen being a glycoprotein with srr-2 encoding the protein backbone. Like the highly glycoslyated native Fap-1 protein from S. parasanguinis (Wu et al., 1998), the GBS-derived $\varepsilon$ antigen could not be visualized by conventional protein staining, while this was not the case for the recombinant product. More extensive biochemical analysis of native GBS Srr proteins, as well as mutagenesis studies, will help to clarify the molecular basis for GBS cell surface $\varepsilon$ expression, whether the anti- $\varepsilon$ antibodies differentiate between protein and/or carbohydrate epitopes, and the contribution of putative glucosyltransferase (GTF) and other accessory genes within the variant GBS secY2/A2 loci to this antigenic reactivity.

Although a long-sought goal and the focus of promising research (Law et al., 2005; Lindahl et al., 2005; Maione et al., 2005), a GBS vaccine is not yet available. A reduction in the incidence of early-onset neonatal GBS infections has been achieved by intrapartum treatment of colonized women with high-dose intravenous antibiotics (Schrag et al., 2000; Puopolo et al., 2005), but this approach currently does not take into consideration potential differences in relative risk associated with different lineages of GBS. As many as $30 \%$ of pregnant women are colonized with GBS, although fewer than $1 \%$ of colonized women give birth to infants who develop invasive GBS infections (Boyer et al., 1983; Baker \& Edwards, 2001). The results presented in this report have obvious clinical relevance. Serotype III organisms account for a substantial proportion of invasive GBS disease, including meningitis and early- and late-onset neonatal sepsis. As serotype III GBS that contain srr-2 are significantly more virulent than srr-1-containing strains, and the srr-2containing RDP III-3/ST-17 lineage can readily be identified by the cell surface expression of the antigenic marker $\varepsilon$, a rapid diagnostic test to detect $\varepsilon$ on clinical isolates promises to be a useful tool to identify those patients, particularly pregnant women, who may be specifically targeted for prophylactic antibiotic therapy during labour and delivery.

\section{ACKNOWLEDGEMENTS}

This project was supported by the University of Florida College of Dentistry, National Institutes of Dental and Craniofacial Research (NIDCR) Training Grant DE 07200, RO1 AI40918 and P30 CA21765 from the National Institutes of Health, the American Lebanese Syrian Associated Charities (ALSAC), the Thrasher Research Fund, the James Madison University Program of Grants for Faculty Assistance, and, in part, by the Department of Energy-funded (DEFG09-93ER-20097) Center for Plant and Microbial Complex Carbohydrates. 


\section{REFERENCES}

Adderson, E. E., Takahashi, S., Wang, Y., Armstrong, J., Miller, D. V. \& Bohnsack, J. F. (2003). Subtractive hybridization identifies a novel predicted protein mediating epithelial cell invasion by virulent serotype III group B Streptococcus agalactiae. Infect Immun 71, 6857-6863.

Areschoug, T., Stalhammar-Carlemalm, M., Karlsson, I. \& Lindahl, G. (2002). Streptococcal beta protein has separate binding sites for human factor H and IgA-Fc. J Biol Chem 277, 12642-12648.

Auperin, T. C., Bolduc, G. R., Baron, M. J., Heroux, A., Filman, D. J., Madoff, L. C. \& Hogle, J. M. (2005). Crystal structure of the Nterminal domain of the group B Streptococcus alpha C protein. J Biol Chem 280, 18245-18252.

Baker, C. J. \& Edwards, M. S. (2001). Group B streptococcal infections. In Infectious Diseases of the Fetus and Newborn Infant, pp. 1091-1156. Edited by J. S. Remington \& J. O. Klein. Philadelphia, PA: W. B. Saunders.

Bensing, B. A. \& Sullam, P. M. (2002). An accessory sec locus of Streptococcus gordonii is required for export of the surface protein GspB and for normal levels of binding to human platelets. Mol Microbiol 44, 1081-1094.

Bensing, B. A., Lopez, J. A. \& Sullam, P. M. (2004). The Streptococcus gordonii surface proteins GspB and Hsa mediate binding to sialylated carbohydrate epitopes on the platelet membrane glycoprotein Ibalpha. Infect Immun 72, 6528-6537.

Bevanger, L. (1985). The Ibc proteins of group B streptococci: isolation of the alpha and beta antigens by immunosorbent chromatography and test for human serum antibodies against the two antigens. Acta Pathol Microbiol Immunol Scand Sect B Microbiol 93, 113-119.

Bisharat, N., Crook, D. W., Leigh, J., Harding, R. M., Ward, P. N., Coffey, T. J., Maiden, M. C., Peto, T. \& Jones, N. (2004). Hyperinvasive neonatal group $\mathrm{B}$ streptococcus has arisen from a bovine ancestor. J Clin Microbiol 42, 2161-2167.

Bohnsack, J. F., Takahashi, S., Detrick, S. R., Pelinka, L. R., Hammitt, L. L., Aly, A. A., Whiting, A. A. \& Adderson, E. E. (2001). Phylogenetic classification of serotype III group B streptococci on the basis of hylB gene analysis and DNA sequences specific to restriction digest pattern type III-3. J Infect Dis 183, 1694-1697.

Bohnsack, J. F., Whiting, A. A., Bradford, R. D., Van Frank, B. K., Takahashi, S. \& Adderson, E. E. (2002). Long-range mapping of the Streptococcus agalactiae phylogenetic lineage restriction digest pattern type III-3 reveals clustering of virulence genes. Infect Immun 70, 134-139.

Boyer, K. M., Gadzala, C. A., Kelly, P. D., Burd, L. I. \& Gotoff, S. P. (1983). Selective intrapartum chemoprophylaxis of neonatal group $B$ streptococcal early-onset disease. II. Predictive value of prenatal cultures. J Infect Dis 148, 802-809.

Brady, L. J., Daphtary, U. D., Ayoub, E. M. \& Boyle, M. D. (1988). Two novel antigens associated with group B streptococci identified by a rapid two-stage radioimmunoassay. J Infect Dis 158, 965-972.

Brady, L. J., Hofig, A., Addison, M. N. \& Lim, D. V. (1996). Association of two antigens, delta and epsilon, with pathogenic serotype III group B streptococci. Proceedings of the 96th General Meeting of the American Society for Microbiology, abstract no. B-350. Washington, DC: American Society for Microbiology.

Chen, Q., Wu, H. \& Fives-Taylor, P. M. (2002). Construction of a novel transposon mutagenesis system useful in the isolation of Streptococcus parasanguis mutants defective in Fapl glycosylation. Infect Immun 70, 6534-6540.
Chun, C. S., Brady, L. J., Boyle, M. D., Dillon, H. C. \& Ayoub, E. M. (1991). Group B streptococcal C protein-associated antigens: association with neonatal sepsis. J Infect Dis 163, 786-791.

Cleat, P. H. \& Timmis, K. N. (1987). Cloning and expression in Escherichia coli of the Ibc protein genes of group B streptococci: binding of human immunoglobulin $\mathrm{A}$ to the beta antigen. Infect Immun 55, 1151-1155.

Davies, H. D., Jones, N., Whittam, T. S., Elsayed, S., Bisharat, N. \& Baker, C. J. (2004). Multilocus sequence typing of serotype III streptococcus and correlation with pathogenic potential. J Infect Dis 189, 1097-1102.

Farley, M. M. (2001). Group B streptococcal disease in nonpregnant adults. Clin Infect Dis 33, 556-561.

Ferrieri, P. (1985). GBS infections in the newborn infant: diagnosis and treatment. Antibiot Chemother 35, 211-224.

Fischetti, V. A., Pancholi, V. \& Schneewind, O. (1990). Conservation of a hexapeptide sequence in the anchor region of surface proteins from gram-positive cocci. Mol Microbiol 4, 1603-1605.

Fleming, K. E., Bohnsack, J. F., Palacios, G. C., Takahashi, S. \& Adderson, E. E. (2004). Equivalence of high-virulence clonotypes of serotype III group B Streptococcus agalactiae (GBS). J Med Microbiol 53, 505-508.

Glaser, P., Rusniok, C., Buchrieser, C. \& 9 other authors (2002). Genome sequence of Streptococcus agalactiae, a pathogen causing invasive neonatal disease. Mol Microbiol 45, 1499-1513.

Gravekamp, C., Horensky, D. S., Michel, J. L. \& Madoff, L. C. (1996). Variation in repeat number within the alpha C protein of group B streptococci alters antigenicity and protective epitopes. Infect Immun 64, 3576-3583.

Handley, P. S., Correia, F. F., Russell, K., Rosan, B. \& DiRienzo, J. M. (2005). Association of a novel high molecular weight, serine-rich protein (SrpA) with fibril-mediated adhesion of the oral biofilm bacterium Streptococcus cristatus. Oral Microbiol Immunol 20, 131-140.

Héry-Arnaud, G., Bruant, G., Lanotte, P., Brun, S., Rosenau, A., van der Mee-Marquet, N., Quentin, R. \& Mereghetti, L. (2005). Acquisition of insertion sequences and the GBSil intron by Streptococcus agalactiae isolates correlates with the evolution of the species. J Bacteriol 187, 6248-6252.

Johnson, D. R. \& Ferrieri, P. (1984). Group B streptococcal Ibc protein antigen: distribution of two determinants in wild-type strains of common serotypes. J Clin Microbiol 19, 506-510.

Jones, N., Bohnsack, J. F., Takahashi, S. \& 9 other authors (2003). Multilocus sequence typing for group B streptococcus. J Clin Microbiol 41, 2530-2536.

Kremer, B. H., van der Kraan, M., Crowley, P. J., Hamilton, I. R., Brady, L. J. \& Bleiweis, A. S. (2001). Characterization of the sat operon in Streptococcus mutans: evidence for a role of Ffh in acid tolerance. J Bacteriol 183, 2543-2552.

Law, M. R., Palomaki, G., Alfirevic, Z., Gilbert, R., Heath, P., McCartney, C., Reid, T. \& Schrag, S. (2005). The prevention of neonatal group B streptococcal disease: a report by a working group of the Medical Screening Society. J Med Screen 12, 60-68.

Lindahl, G., Stalhammar-Carlemalm, M. \& Areschoug, T. (2005). Surface proteins of Streptococcus agalactiae and related proteins in other bacterial pathogens. Clin Microbiol Rev 18, 102-127.

Luan, S. L., Granlund, M., Sellin, M., Lagergard, T., Spratt, B. G. \& Norgren, M. (2005). Multilocus sequence typing of Swedish invasive group B streptococcus isolates indicates a neonatally associated genetic lineage and capsule switching. J Clin Microbiol 43, 3727-3733.

Maeland, J. A., Brakstad, O. G., Bevanger, L. \& Kvam, A. I. (1997). Streptococcus agalactiae beta gene and gene product variations. J Med Microbiol 46, 999-1005. 
Maione, D., Margarit, I., Rinaudo, C. D. \& 24 other authors (2005). Identification of a universal Group B Streptococcus vaccine by multiple genome screen. Science 309, 148-150.

Martin, T. R., Rubens, C. E. \& Wilson, C. B. (1988). Lung antibacterial defense mechanisms in infant and adult rats: implications for the pathogenesis of group B streptococcal infections in the neonatal lung. J Infect Dis 157, 91-100.

Michel, J. L., Madoff, L. C., Kling, D. E., Kasper, D. L. \& Ausubel, F. M. (1991). Cloned alpha and beta C-protein antigens of group B streptococci elicit protective immunity. Infect Immun 59, 2023-2028.

Michon, F., Brisson, J. R., Dell, A., Kasper, D. L. \& Jennings, H. J. (1988). Multiantennary group-specific polysaccharide of group $B$ Streptococcus. Biochemistry 27, 5341-5351.

Musser, J. M., Mattingly, S. J., Quentin, R., Goudeau, A. \& Selander, R. K. (1989). Identification of a high-virulence clone of type III Streptococcus agalactiae (group B Streptococcus) causing invasive neonatal disease. Proc Natl Acad Sci U S A 86, 4731-4735.

Nagano, Y., Nagano, N., Takahashi, S., Murono, K., Fujita, K., Taguchi, F. \& Okuwaki, Y. (1991). Restriction endonuclease digest patterns of chromosomal DNA from group B beta-haemolytic streptococci. J Med Microbiol 35, 297-303.

Puopolo, K. M., Madoff, L. C. \& Eichenwald, E. C. (2005). Early-onset group $\mathrm{B}$ streptococcal disease in the era of maternal screening. Pediatrics 115, 1240-1246.

Reed, L. J. \& Muench, M. H. (1938). A simple method of estimating fifty per cent endpoints. Am J Hyg 27, 493-497.

Rodewald, A. K., Onderdonk, A. B., Warren, H. B. \& Kasper, D. L. (1992). Neonatal mouse model of group B streptococcal infection. $J$ Infect Dis 166, 635-639.

Rubens, C. E. \& Heggen, L. (1988). Tn916 $\mathrm{E}$ : a Tn916 derivative expressing erythromycin resistance. Plasmid 20, 137-142.

Russell-Jones, G. J. \& Gotschlich, E. C. (1984). Identification of protein antigens of group B streptococci, with special reference to the Ibc antigens. J Exp Med 160, 1476-1484.

Sambrook, J., Fritsch, E. F. \& Maniatis, T. (1989). Molecular Cloning: a Laboratory Manual, 2nd edn. Cold Spring Harbor, NY: Cold Spring Harbor Laboratory.

Schrag, S. J., Zywicki, S., Farley, M. M. \& 7 other authors (2000). Group B streptococcal disease in the era of intrapartum antibiotic prophylaxis. N Engl J Med 342, 15-20.

Seifert, K. N., McArthur, W. P., Bleiweis, A. S. \& Brady, L. J. (2003). Characterization of group B streptococcal glyceraldehyde-3-phosphate dehydrogenase: surface localization, enzymatic activity, and proteinprotein interactions. Can J Microbiol 49, 350-356.

Siboo, I. R., Chambers, H. F. \& Sullam, P. M. (2005). Role of SraP, a serine-rich surface protein of Staphylococcus aureus, in binding to human platelets. Infect Immun 73, 2273-2280.

Staden, R. (1996). The Staden sequence analysis package. Mol Biotechnol 5, 233-241.

Stalhammar-Carlemalm, M., Stenberg, L. \& Lindahl, G. (1993). Protein rib: a novel group B streptococcal cell surface protein that confers protective immunity and is expressed by most strains causing invasive infections. J Exp Med 177, 1593-1603.

Stephenson, A. E., Wu, H., Novak, J., Tomana, M., Mintz, K. \& FivesTaylor, P. (2002). The Fapl fimbrial adhesin is a glycoprotein: antibodies specific for the glycan moiety block the adhesion of Streptococcus parasanguis in an in vitro tooth model. Mol Microbiol 43, 147-157.

Takahashi, S., Adderson, E. E., Nagano, Y., Nagano, N., Briesacher, M. R. \& Bohnsack, J. F. (1998). Identification of a highly encapsulated, genetically related group of invasive type III group B streptococci. J Infect Dis 177, 1116-1119.

Takahashi, Y., Konishi, K., Cisar, J. O. \& Yoshikawa, M. (2002). Identification and characterization of $h s a$, the gene encoding the sialic acid-binding adhesin of Streptococcus gordonii DL1. Infect Immun 70, 1209-1218.

Takahashi, Y., Yajima, A., Cisar, J. O. \& Konishi, K. (2004). Functional analysis of the Streptococcus gordonii DL1 sialic acid-binding adhesin and its essential role in bacterial binding to platelets. Infect Immun 72, 3876-3882.

Takamatsu, D., Bensing, B. A. \& Sullam, P. M. (2004a). Four proteins encoded in the $g s p B-s e c Y 2 A 2$ operon of Streptococcus gordonii mediate the intracellular glycosylation of the platelet-binding protein GspB. J Bacteriol 186, 7100-7111.

Takamatsu, D., Bensing, B. A. \& Sullam, P. M. (2004b). Genes in the accessory sec locus of Streptococcus gordonii have three functionally distinct effects on the expression of the platelet-binding protein GspB. Mol Microbiol 52, 189-203.

Tettelin, H., Masignani, V., Cieslewicz, M. J. \& 40 other authors (2002). Complete genome sequence and comparative genomic analysis of an emerging human pathogen, serotype V Streptococcus agalactiae. Proc Natl Acad Sci U S A 99, 12391-12396.

Tettelin, H., Masignani, V., Cieslewicz, M. J. \& 43 other authors (2005). Genome analysis of multiple pathogenic isolates of Streptococcus agalactiae: implications for the microbial "pan-genome". Proc Natl Acad Sci U S A 102, 13950-13955.

Tyrrell, G. J., Senzilet, L. D., Spika, J. S., Kertesz, D. A., Alagaratnam, M., Lovgren, M. \& Talbot, J. A. (2000). Invasive disease due to group B streptococcal infection in adults: results from a Canadian, population-based, active laboratory surveillance study 1996. Sentinel Health Unit Surveillance System Site Coordinators. J Infect Dis 182, 168-173.

Ustinovitch, I., Vlasov, G., Totolyan, A. \& Suvorov, A. (1999). Cloning and expression of gene fragment IgA-binding protein of group B streptococci. Folia Microbiol (Praha) 44, 726-728.

Wilkinson, H. W. \& Eagon, R. G. (1971). Type-specific antigens of group B type Ic streptococci. Infect Immun 4, 596-604.

Wu, H. \& Fives-Taylor, P. M. (1999). Identification of dipeptide repeats and a cell wall sorting signal in the fimbriae-associated adhesin, Fap1, of Streptococcus parasanguis. Mol Microbiol 34, 1070-1081.

Wu, H., Mintz, K. P., Ladha, M. \& Fives-Taylor, P. M. (1998). Isolation and characterization of Fap1, a fimbriae-associated adhesin of Streptococcus parasanguis FW213. Mol Microbiol 28, 487-500. 